This item was submitted to Loughborough's Research Repository by the author.

Items in Figshare are protected by copyright, with all rights reserved, unless otherwise indicated.

\title{
"I just remember rugby": re-membering physical education as more than a sport
}

PLEASE CITE THE PUBLISHED VERSION

http://dx.doi.org/10.1080/02701367.2014.977430

\section{PUBLISHER}

Taylor and Francis / @ SHAPE America

\section{VERSION}

AM (Accepted Manuscript)

\section{PUBLISHER STATEMENT}

This work is made available according to the conditions of the Creative Commons Attribution-NonCommercialNoDerivatives 4.0 International (CC BY-NC-ND 4.0) licence. Full details of this licence are available at: https://creativecommons.org/licenses/by-nc-nd/4.0/

\section{LICENCE}

CC BY-NC-ND 4.0

\section{REPOSITORY RECORD}

Casey, Ashley, and Mikael Quennerstedt. 2019. ""I Just Remember Rugby": Re-membering Physical Education as More Than a Sport". figshare. https://hdl.handle.net/2134/19535. 
“I just remember rugby”: Re-membering Physical Education as More Than a Sport Ashley Casey

Loughborough University, Loughborough, LE11 3TU, UK.

Phone: (+44) 1509226314, A.J.B.Casey@lboro.ac.uk

University of Limerick, Limerick, Ireland

and

Mikael Quennerstedt

Örebro University, Örebro, Sweden 


\begin{abstract}
Purpose: The purpose of this paper was to investigate how boys communicate previous experiences of cultural norms in PE-practice. This is done by analyzing what boys (from a school in the UK) remember about PE two years after they last participated. Making use of autobiographical memory theory and John Dewey’s notions of re-actualisation of experience and collateral learning we discuss the results of the study in terms of remembering. Method: The participants in this study were twenty boys from a secondary school in the UK. At the time of the study eleven of the boys were aged between 16 and 17 and nine were aged between 17 and 18. These boys were interviewed using a semi-structured approach to explore their autobiographical memories of PE. Results: The overarching 'logic' of memories of PE was sport. Almost all of the boys articulated memories were of doing sports, albeit in various capacities. Beyond the main theme the paper positions the boys' recollections against established cultural norms of PE as a social practice and explores three sub-themes: (a) Just doing the game in a traditional curriculum though a multi-activity sport discourse; (b) Learning the games in a technical sport discourse; and (c) Learning beyond the game around an educational sport discourse. Conclusion(s): These boys’ re-actualized memories of learning within an educational discourse, which suggests that what they learnt goes beyond the simple consequence of participating.
\end{abstract}

Keywords: Autobiographical memory, learning, cultural norms, models-based practice 
“I just remember rugby”: Re-membering Physical Education as More Than a Sport Physical Education (PE) is not only defined or constituted by what is written about it, but also by what different actors like physical educators or students do in its name. More importantly perhaps, we would argue that it is also defined by what teachers, parents, support staff and administrators remember about what was done in its name when they were students themselves. The memories we hold of school have considerable currency in the ways in which we communicate and make decisions about the current and future state of education. However, psychological and educational research has been much more concerned with policy, testing, examinations and the acquisition of general knowledge rather than the specifics of how or when knowledge was acquired (Pillemer, Picarfiello, Law, \& Reichman, 1996).

When prior experiences of PE are considered in settings where adults are expected to engage with, and advocate for PE, then these experiences have a very real potential to adversely impact on the experiences of subsequent generations. Indeed, unless we know more about what is remembered of PE, and how these experiences are re-actualized in the present, we are poorly equipped to improve what occurs in our gyms in the future. Fundamentally we need to know what young people are remembering about their PE experiences so that we can begin to draw conclusions about the types of PE that improve student experience. It is through exploratory steps, such as the ones we take in this study, that we can begin to comprehend the impact PE can have on peoples’ future attitude towards physical activity. By taking young people back to re-experience their past in PE our understanding is enhanced in regard to PE, sport, learning, and affective experience in the present, with the potentially, in the future, to gain an even fuller understanding. This initial study offers the potential for a longitudinal exploration of students' memories of physical education and young peoples’ future attitudes towards it.

The purpose of this paper, therefore, was to investigate how boys communicate 
previous experiences of cultural norms in PE-practice. This was done by analyzing what boys remember about PE two years after they last participated in it. Making use of autobiographical memory theory and John Dewey’s notions of re-actualisation of experience and collateral learning we then discuss the results of the study in terms of re-membering.

\section{Autobiographical Memory}

In her seminal work around autobiographical memory (AM), Tulving (1983) argued that the common conception of school is that children "learn skills and knowledge that they need for life. They do not go to school in order to acquire a storehouse of temporally dated personal memories” (p. 51). Yet, that is what students often acquire: both the specific and the general. Simply put, the teacher does more than impart general knowledge. He or she interacts, converses and comments on work, attitude and aptitude, each of which in turn influences a person's approach to individual subjects and/or to school itself. In considering the value of remembering in these processes, Schacter, Gutchess, and Kensinger (2009, p. 104) argued, "whether a society remembers its past in a specific or general manner should have important consequences for how that society views itself.” If this is shifted to education it becomes clear that our memories of school play a significant role in the way we construct the fabric of such places in our current social interactions and decision-making processes.

In considering the specificity of memory with regards to present day actions and the decisions we make it is useful to define AM. Williams and Conway (2009, p. 33) position AM as constituting episodic memory (memory for specific episodes) and generic, conceptual, and schematic knowledge of their personal histories. It is in bringing together of these two types of knowledge that “one’s life is recalled.” Boyer (2009) held that AM afforded humans the capacity to re-experience past situations or to engage in "mental time-travel” (p. 5).

AMs, therefore, “are transitory dynamic mental constructions generated from the underlying knowledge base” (Williams \& Conway, 2009, p. 38). We would argue that in 
considering the dynamism of such memories it seems remiss not to have considered the impact that AM has had on the social construction of school and more specifically PE. We would argue that these specific memories have often been overlooked in educational research, and yet, as Williams and Conway (2009, p. 33) suggest, it is these memories that "locate us in sociohistorical time...in our societies and in our social groups, they define the self."

\section{Re-actualizing and Re-membering}

Applying these ideas to education and using the seminal work of John Dewey, it is possible to go beyond the psychological/cognitive perspective of Tulving and Thomson (1973) and others (that speaks of information) and towards the constructivist perspective of Dewey and his notion of re-actualization of experience. Even if Dewey did not write about memories per se, he connects past, present and future continuities of experience through the ways in which we bring something from previous experiences into the present and thereby modify experiences to come (Dewey, 1938). To learn from experience is subsequently to connect the past (previous experiences) with the future (the direction of experiences). As Dewey argues:

Past experiences are retained so that they may be evoked and arranged when there is need to use them in attaining the new end set by the needs of our affective nature. But the retention is not intellectual. It is a matter of organic modifications, of change of disposition, attitude and habit. The "stuff” from which thinking draws its material in satisfying need by establishing a new relation to the surroundings is found in what, with some extension of the usual sense of the word, may be termed habits; namely the changes wrought in our ways of acting and undergoing by prior experiences (Dewey, 1926, p. 106).

In this re-actualization process, the boys in our study can be seen to be reflecting on their experiences of PE practice, connecting past, present and future, and thus becoming re- 
members of their PE-practice. Memories are then about re-actualizing experiences in a social context rather than something exclusively cognitive. In remembering their PE experiences, these boys, in some ways, become members of their classes again.

As we previously argued, this study can offer insights into the significance of specific memories of lessons alongside the general knowledge acquisition that is seen as the function of schooling. Here Dewey can again help us with his concept of collateral learning, the subtle and indirect aspects of education that form enduring attitudes.

Collateral learning in the way of formation of enduring attitudes of likes and dislikes, may be and often is of much more importance than the spelling lesson or lesson in geography or history that is learned. For these attitudes are fundamentally what count in the future (Dewey, 1938, p. 49)

Collateral learning, which has many similarities with what Jackson (1968) called the hidden curriculum, is thus the learning occurring while the PE teacher is busy in the enterprise of teaching skills and subject content in the gym. Yet perhaps it is this collateral learning that has the greatest significance on what teachers, parents, support staff and administrators remember (of when they were students) about what PE is and does - in other words on how it is constituted. Williams and Conway (2009) suggest that memories are historically located as a social practice in society. So by focusing on the cultural norms of PE as a social practice constituted in their autobiographical stories we can say something about the collateral learning that the students re-actualized and potentially have learned in their PE lessons.

\section{Autobiographical Memory in Physical Education}

In one of the first studies to use AM in PE, Sinelnikov and Hastie (2010) explored students’ AMs of PE through their engagement in multiple seasons of Sport Education. The participants' strongest and most detailed memories were of the specific events and salient features of the model such as working in teams, awards and certificates, officiating, and 
training, practicing and playing. In other words, their memories were of the specifics of events and teacher/students actions and interactions and not a generalized understanding of PE per se.

In one of the few papers to explore participants' memories of PE, Thomas (1985) asked how women's experiences of PE at school influenced their future attitudes towards exercise and positive health promotion. When asked what they 'remembered about PE' just over half immediately recalled hockey as the most 'hated' activity, one that Thomas (1985) believed adversely affected their memories of PE. Indeed, hockey was reported as 'what they did most', to such a degree that these women might appear to have done very little else in PE. When these memories were combined with feelings that, as girls, these women were compelled to take part in a competitive sport that they were ill-suited to succeed at, memories of PE continued to be negative. This ‘forced’ participation caused feelings of uselessness, clumsiness and a lack of skill that persisted into adulthood. Indeed, Thomas (1985) concluded that participants' reconnection with an activity they disliked, and their belief that they were non-athletic and useless, had a lasting impact on their perceptions of physical activity. When these negative experiences are considered in situations where adults are expected to engage with - indeed advocate for $-\mathrm{PE}$, then this negativity has a very real potential to adversely impact on the experiences of a new generation of young people. For example, in their work around non-specialist teachers' confidence in teaching PE, Morgan and Burke (2008) believed that "the influence of school PE experiences may play an important role in the development of attitudes and perceived competencies regarding PE teaching” (p. 4). They went on to suggest that teaching a subject that might hold bad memories, and that perhaps wasn't enjoyed at school, has the potential to negatively impact on the confidence and behavior of future teachers. It does not, therefore, seem a big step to suggest that this 'vicious circle' has the potential to damage the future of the subject. 
However, unless we know more about what is remembered of PE, and how these experiences are re-actualized in the present and inform the future, we remain poorly positioned to make the changes needed to improve what occurs in our gymnasia.

\section{Methods}

\section{Setting}

The study site was a state selective grammar school situated in England. In this type of school an entrance exam is used to identify a subset of children (nationally around the top $25 \%$ in the test) considered suitable for a grammar school education. The school population consisted of predominately white students $(\mathrm{N}=812)$ of which $1.2 \%$ received free school meals and 99.4\% had English as their first language. As students in the school were taught in single sex classes, only boys were involved in this study.

\section{Participants}

The participants in this study were twenty boys. Eleven of the boys were in year 12 (aged 16-17) (i.e. Grade 11 in the US education system) and nine were in year 13 (aged 1718) (i.e. Grade 12 in the US education system). The boys were selected to participate because they had originally been in one of two classes that had (a) been taught by the first author (A1) for four or five years respectively (from age 11 to the age 15 or 16 respectively) for at least one of their single, 40 minute lessons each week; (b) had been taught by A1 for some of their double, 80 minute lessons for 4 or 5 years respectively; (c) had been participants in previous research studies that explored the use of pedagogical models in secondary PE (Casey, 2011, 2013; Casey. Dyson, \& Campbell, 2009; Casey \& Hastie, 2011; Casey, Hastie, \& Rovegno, 2011) and (d) had continued as students in the school past the age of compulsory education (i.e., 16 years old). Six boys would be considered to be of high ability (HA), ten of middle ability (MA) and four of low ability (LA) in PE.

\section{Taught Curriculum and Context}


Our study occurred in specific context and under specific conditions. While it is beyond the scope of this paper to discuss these in detail it is important to at least acknowledge them. If you are interested in understanding the wider context and implications that pertain to this study then please refer to the wider work of Casey (see above). That said it would be hard to argue against the idea that 'an English grammar school education’ comes with certain preconceived notions about what type of PE might occur there. Indeed many of the traditional practices of both PE and a grammar school education were evident in both the curriculum and teaching in this school. That said - and in contrast to the norms of the school -one teacher had adopted a models-based practice (MBP) approach to teaching his lessons. This MBP curriculum constituted his teaching of different curricular areas through the pedagogical models; Cooperative Learning, Sport Education, and Teaching Games for Understanding. It is the comparison between the 'grammar school' curriculum and the MBP curriculum that allows us to construct the different types of PE that were re-membered and re-actualized in this study.

\section{Data Gathering}

Summarizing work in AM stretching back to the 1980s, Pathman, Samson, Dugas, Cabez, and Bauer (2011) suggested that AM is tested by asking children or adults to recall events from their daily life. To this end, A1 used semi-structured interviews to explore the boys' memories of PE. The availability of boys determined whether they were involved in individual, paired or group interviews (ten individuals, two pairs, and two groups of three were interviewed for this study). As the school chose the timings of the interviews, any group or paired interview was randomly, rather than purposefully selected. During the interviews participants were asked to respond to what they remembered about (a) Mr Casey’s Lessons i.e. PE using MBP and, (b) “physical education and games”.

\section{Teacher-as-Researcher}


We acknowledge that the position of A1 as the researcher, the interviewer, and former teacher might be problematic in terms of the credibility of the findings. However, the decision to use this methodological approach was deliberate, and A1 was positioned in the datagathering phase as a 'cue' in the retrieval process, a link between present and past (Boyer, 2009; Williams \& Conway, 2009). Indeed, in a similar vein to Sinelnikov and Hastie (2010) in their work on AM, the teacher in this study was also one of the researchers (cf. Sinelnikov \& Hastie, 2008). The use of what Stenhouse (1975) termed the “teacher-as-researcher” has a strong tradition in educational research through methodologies such as action research (Stenhouse, 1975).

The original decision to have the teacher-as-researcher conduct the interviews was based on the fact that the initial research was undertaken alone. However, there is a strong rationale for the feasible and authenticity of this approach. Firstly, and drawing directly from Sinelnikov and Hastie (2010, p. 169), was the idea "that research on autobiographical memory is principally based on a methodology where participants deliberately recall personally experienced past events in response to a particular word or phrase provided by the experimenter". The second was that memories have been classified as being conceptually related to people, places, objects, and activities (Mace, Clevinger, \& Martin, 2010). By having the teacher as the interviewer it was felt that, as a 'person' (in this case as a teacher), he would be considered as being related to the boys' memories and would therefore act as a visual cue for memory recall. He would be part of the "retrieval environment” i.e., an information link between something remembered "in the past and information present in the immediate cognitive environment of the rememberer” (Tulving \& Thompson, 1973, p. 352).

It was not until the study has been finished and the data was being prepared for analysis that A1 called into question the credibility of the analysis. It was at this point that the second author (A2) was invited to join the research team in an effort to manage bias and 
increase the credibility of these findings. To this end A2 was centrally involved in the analysis of the data and all key decision-making about the interpretation of the findings.

Fundamentally, we believe that in this study the interview situation served as an interview (i.e., a view of PE that had been shared by the boys and their former teacher) and that A1's role as the interviewer helped the boys to retrieve their memories of lessons that he was almost synonymous with. In this way the interview could be regarded as PE re-assembled and co-created in the meeting between a former teacher and his male students. In the analysis of the data, however, A2 played a crucial role to insure credibility together with a distanced critical gaze by involving the theoretical lenses of John Dewey.

\section{Data Analysis}

All the boys had previously reported on their experience of PE and had been given the opportunity to reflect on their involvement in PE generally and pedagogical models specifically (Casey, 2011, 2012, 2013; Casey et al., 2009; Casey \& Hastie, 2011; Casey et al., 2011). However, and in contrast to this current paper, all of these studies occurred at a time when the school employed A1 and data were gathered during and immediately following specific units of work. This paper is unique inasmuch as it reports on the teacher's work as a whole and does not seek to differentiate between different units. An institutional review board approved the research and informed consent was obtained from all participants (all of whom are given pseudonyms in the results section).

In light of these prior experiences we approached the analysis with a specific focus on two analytical questions which are used to help us to better understand how PE, sport, learning, and affective experience from the past is remembered in the present and, potentially, how it might impact on the future:

- How are the boys communicating their previous experiences of PE practice in their autobiographical stories? 
- How are the cultural norms of PE constituted in their autobiographical stories? The first part of the analysis involved categorization into general themes using qualitative content analysis (Elo \& Kyngnäs, 2008). The analytical stages used in the first step were as follows: (a) each interview was read in its entirety by both authors; (b) each interview was used as a unit of analysis, and the interviews were coded by the authors into categories; (c) using a peer examination strategy, the interviews were read independently by the authors and initial categories were compared and modified. Krefting (1991) suggests that a peer examination is a strategy involving a colleague that critically examines the process and the findings, and argued that "this is one way of keeping the researcher honest, and the searching questions may contribute to deeper reflexive analysis by the researcher. Colleagues can also increase credibility by checking categories developed out of data and by looking for disconfirming or negative cases.” (p. 219). While A2 led the use of this strategy it involved an ongoing discussion between both authors. In the second step we analyzed the themes identified in step one in terms of the cultural norms that emerged from the boys' stories. This was done by putting themes into context in relation to Williams and Conway’s (2009) idea that we need to consider memories as a social practice in society.

\section{Credibility}

In seeking to establish credibility A2 (who not had previously been involved in this or other work involving A1) was brought in to engage in what Lincoln and Guba (1985) described as 'peer debriefing' (but which we refer to in this paper as peer examination). Lincoln and Guba (1985) described peer debriefing as “a process of exposing oneself to a disinterested peer... exploring aspects of the inquiry that might otherwise remain only implicit within the inquirer’s mind” (p. 308). Others (cf. Bogden \& Biklen, 1998) have supported the use of such debriefers for reducing the threat of researcher bias.

Fundamentally, and in seeking credibility, this paper sought to meet what Guba and 
Lincoln (1989) described as the hallmarks of naturalistic inquiry. To this end we have sought (a) fairness (a balance of participants' views and voices should be heard), (b) ontological and educative authenticity (a raised level of awareness by individual research participants and those who surround them), and (c) catalytic and tactical authenticities (the ability of the research to prompt action) (Adapted from Guba and Lincoln, 2005, p. 207). Put more simply we have tried to ensure that (a) a range of voices are heard in the results that follow, (b) the realities of school physical education are portrayed, and (c) actionable understanding emerges that might benefit the research and practice communities.

In the following sections the results will initially be explored in terms of what boys remember and re-actualise about PE as a social practice. Following this consideration of the interviews, these results will be discussed as a form of 're-membering' (i.e., to again become members through re-actualization of experience) that seeks to highlight the importance of how PE as a school subject is positioned and valued in society, and how teachers, parents, support staff and administrators communicate and make decisions about the current and future state of PE. In the results we use authentic citations to increase the credibility of the study (Elo \& Kyngnäs, 2008), and elucidate the center and boundaries of each theme.

\section{Results}

Over the four or five years of secondary school PE that these boys were asked to remember, the overarching 'logic' of their re-actualised experiences was sport. Almost all of their articulated memories were of doing sports, albeit in various capacities. Therefore, the results section will explore the boys' remembering of PE and games through the main theme: Sport as an overarching logic. This is not surprising, and a plethora of research has shown how a logic of sports has dominated the subject content of PE (c.f. Kirk, 2012; Öhman \& Quennerstedt, 2008; Siedentop, 1994). However, despite the notion that PE meant sport, there was also a real sense that the boys remembered sport in different ways. 
The assumption of this study, from the outset, was that the boys would remember two distinct notions; (a) physical education using models-based practices occurring in their single 40 minute PE lessons; and (b) physical education and games taught in their double 80 minute PE lesson. Indeed, it was the expectation around the very nature of this memory division that initially prompted this research. That said, while there may have been some fundamental problems with the teacher-as-researcher's assumption that the boys' memories could so finely distinguish between double and single lessons, it does seem that the boys certainly remembered their PE experiences in a manner that was in keeping with these expectations. Consequently beyond the main theme, sport as an overarching logic, further discussions will occur that seek to explore each of the identifiable forms of PE that the boys recalled. In considering these themes in light of the literature it became clear that they are linked to established cultural norms of PE as a social practice. Therefore the paper also explores three sub-themes: (a) Just doing the game in a traditional curriculum though a multi-activity sport discourse; (b) Learning the games in a technical sport discourse; and (c) Learning beyond the game around an educational sport discourse.

\section{Sports as an Overarching Logic}

Doing sports is something that is evident in almost all the boys' memories, and participating in PE, illustrated through their memories, involves becoming members of sport as a social practice (cf. Kirk, 2012). While the term “physical education and games” and the idea of PE using MBP were used to explore different aspects of these boys’ membership of both school classes (in single lessons) and ability groupings (in double lessons), their abiding memories were of sport. When Steve (MA) was asked to remember MBP lessons he said that it was "more of a structure to each lesson instead of just playing a random sport for an hour and 20 minutes.” Dan (MA) recalled that “we were just told, right, this week we're doing swimming, this week we're doing this sport.” Guy (HA) simply stated, “it [physical PE and 
games] just gave me a nice opportunity to engage in other sports I wouldn’t have done.”

While the tradition in the school was one where ability groups were used in the double games lesson and classes were taught in tutor groups (i.e., in mixed ability classes) in single PE lessons, the focus wasn't consciously on sport. While traditional terms of reference such as “the A group”, “the B Group”, “the squad”, “the non-squad”, and "the team” were used to describe those in different games groups, the emphasis was predominantly on team games and not sports per se (Kirk, 2012). Yet, the boys recalled a focus on a discourse around sport, and one that wasn't challenged in the course of these interviews. Alex (HA) suggested that what he would remember most about PE and games was:

Five years of sports, I mean, I came into the school, I'd already done a bit of sports before, but for many people it was sort of the first real serious sports lessons they had, but I personally feel I’ve developed a lot.

Even when asked to explore the distinctions between the approach taken in different lessons Alex (HA) felt that although MBP “changed my mind set” he was still focused on the fact that it was sports that stopped "being a bad thing” and not PE.

Sports in terms of both games and individual sports thus sets the boundaries for what cultural norms the boys are participating in and through their memories become re-members of. This will be developed within each sub-theme. However, it is clear from the findings that sports and the logic of sports is something that is taken for granted in all the interviews and it is important that, as you read on, this idea is kept firmly in mind.

\section{Just Doing the Game in a Traditional Curriculum Within a Multi-Activity Sport}

Discourse. Remembering PE and games was very much about traditional sports experienced in seasonal blocks that were repeated year on year (cf. Kirk, 2012). Steve (MA) recalled that they [the boys] played "rugby in the winter and tennis in the summer", which is a simplification of the multi-sports curriculum that operated across the five years of the 
program. 'Games lessons’ were a place where rugby, track and field athletics, cross-country running, tennis, cricket, softball, hockey, football, and water polo all occurred. Indeed, the idea that 'games' was something to be experienced across a carousel of short units is certainly in keeping with previous findings (Pühse \& Gerber, 2005). Edward (HA) recalled “we didn’t focus too long on one sport, for example, we didn't just focus on football, and so it didn’t just encourage those who were good at a particular sport to feel as though they were superior”. Here it was more about doing than learning sports (MacPhail, Kinchin, \& Kirk, 2003).

However, such was the prevalence of rugby that every student recalled 'doing it'. In fact it could be argued that for some boys rugby was THE way of doing 'games'. Dan (MA) recalled that in games “there was rugby. What else did we do...what else did I do? ” Similarly Tom (MA) re-membered “doing a lot of rugby”, while Luke (MA) suggested that "all I remember of games, really, is rugby”. Steve (MA) felt that his most important memory was "learning to play rugby and moving up through the rugby team, like, through the different levels that we had and trying to get into the rugby team”.

The cultural norms embedded in the game of rugby thus occupy a hegemonic position of their participation (Crum, 1993; Thomas, 1985). However, of equal significance were their memories of how 'games' was taught. Steve (MA) recalled that:

Once I was in the rugby team...there was a lot of repetition in it, to get moves properly done, and it was, it was probably, it wasn’t changed often and then, like, it was just sort of passing drills and there may be a match at the end. There was no difference to it, or any originality.

Other boys remembered that games lessons followed a very structured format. Richard (LA) said "lessons [were] on passing techniques, rules and different exercise, and then we took that into the actual game to see how well we performed”. Similarly Guy (HA) felt that games had been about "enjoyment, [and] fun” yet felt that it was "over-coached ...emphasis on winning, 
emphasis on satisfaction as a team and individual responsibility within a team”.

Within the overriding logic of sport, the role of the student in this traditional curriculum was that of being a player (MacPhail et al., 2003). PE and Games was a place to do traditional gender-specific team games where boys were 'seen' as players who were positioned in vertical hierarchies based on their respective playing ability (i.e., top group or bottom group). Under this notion of PE, the development of team play was of much greater importance than learning about the sport or themselves, and the role of an individual seems to be only of importance within the wider team's performance. Indeed, learning was not the key aspect of games that many boys remembered. Instead "the most important aspect was winning the games" (Guy (HA)) and "being on the winning side” (Richard (LA)), which is in line with logics of competitive sports, so often identified and criticized within PE practice (Ennis, 1996, 2006). That is not to say that these boys were opposed to this discourse around PE, and in many cases the boys certainly seemed to buy into the common expectation around PE. Winning was important and for boys such as Aaron (HA) it was, perhaps, one of the guilty pleasures of doing sports:

I think some of the best memories were probably just the ones of, sort of, like, the satisfaction, sounds kind of bad, but the winning, I guess and, like, being able to achieve something and being successful at a sport, when previously I wouldn’t have thought of myself as too much of a sports person all-rounder. The lamentable thing, however, was that there was little in these memories to differentiate the experiences of these boys from the ones reported on in PE research the world over (Pühse \& Gerber, 2005). Indeed, given what has been written about our subject there was little to distinguish when, in the last fifty years, these boys might have been taught. Such was the generality of these boys' games experiences that there was little - except maybe for the fact that the game was rugby - to tie their comments to a particular type of school, country or 
indeed time period (Kirk, 2012; Casey, 2014). What was evident, however, was their complicity in maintaining the cultural norms of a traditional discourse around the role of team games in teaching teamwork, cooperation and responsibility, and the idea that PE was just a break from normal lessons, as Matt (MA) suggested:

Because it’s like a break from all the other subjects, and for me it was, like, I didn’t have to, well, I liked it, and, as I say, I didn’t have to, there was no pressure to revise or to get my work up to speed.

For some boys 'games’ was something to “get through”, as it was viewed as being unimportant in the grand scheme of things. Other boys felt that they were made to do things that they had little, if any, choice in and that nothing significant came of their lessons: Luke (MA): always remember, yeah, just playing a couple of matches on the field, doing all these drills and, yeah, it seemed like endless passing of the ball. Because I never really enjoyed it [rugby], it never, I don’t know, I never really... Tom (MA): Got into it.

Luke (MA): Yeah, exactly. I never really got into it, understood it, so that's all I remember, really. Not so positive memories of games.

Indeed for some boys PE and Games were quite unimportant. When asked to describe his most important memory of PE and Games John (MA) felt that he didn’t have any:

I don't really like that question, because important, I don't think that any of the memories that I have are very important. It was a fun lesson, but, for me, that's not where I'm heading so, like, doing PE for four years, and memories from that, I don't know I can categorize ones that are most important.

In line with other studies (c.f. Sinelnikov \& Hastie, 2010), this sub-theme illustrates an idea of PE as just doing games where the purpose was for boys to try different sports. Moreover, enjoyment of the game is the valued outcome of the lesson (cf. Siedentop, 1994). 
Learning the Games Within a Technical Sport Discourse. When their memories of the focus in the lessons shifted away from the preponderance of team games and instead focused on the lessons taught through a MBP approach, the role of the student in PE changed as well. The emphasis was much less on student-as-player and much more on student-aslearner. That said, a lot of these lessons were remembered through a clear sports discourse under which the boys, as other studies also show (Kirk, 2012; Wallhead, Hagger, \& Smith, 2012), were positioned as learners of 'real sports'. While they remembered being taught about techniques, tactics, and strategies there were also memories of how to develop knowledge about being both better players and what it meant to play. However, these 'single' lessons were used to initially pilot and then maintain a MBP approach to teaching which these boys attended for four or five years respectively. While the findings from MBP have been reported elsewhere (see Casey and colleagues) it is significant to note that the emphasis in these units was on transfer of learning across different sports. For example, an invasion games unit included successive basketball and water polo experiences in which the themes of scoring, progression and possession were linked with the ideas of scoring, passing and dribbling. In this way skills, tactics and strategies were linked and extended (cf. Parker \& Curtner-Smith, 2012), rather than the opportunity to try skills out in a game that boys cited in the previous sub-theme.

The boys' memories in this sub-theme center on what they learned in relation to sports and were often in contrast to the memories of just doing games. In other words, the things they learnt became more important than what they did. However, while this learning focused on development - be it of skills or understanding - it was also about values in and of sport, such as competition, winning and losing, teamwork, and working in a good atmosphere that was conducive to learning, rather than the narrow focus on winning that occurred in games. As previous studies have highlighted (Kirk, 2012; Wallhead et al., 2012), these cultural norms 
are reasonable within a technical sports discourse where the learning of skills, techniques and a narrow focus of competition are at the forefront.

Will (HA) suggested that the classroom structure in the MBP lessons “wasn’t sort of slapdash”, a point independently supported by Oliver (MA) who suggested that "it felt like there was a purpose to it, it wasn’t just pointless pratting around”. The boys certainly saw the variance between the different teachers’ approaches to their lessons, indeed to their learning. Much of this was to do with the structure of the lessons, and it was for this that the differences between ‘double' or 'single’ lessons are most remembered:

Edward (HA): I remember them always being quite structured. We always knew what we were doing. There was never any, like, no one was ever really confused as to what was going on, so it was, none of us didn’t know what to do.

Richard (MA): Lessons were very well structured. They kind of took a different aspect, rather than just playing the games, they kind of looked into detail about what was involved in playing, techniques and things like that, and it kind of broke the game up and made you think, well, how to play, and the benefits you could get. When we played that in the actual full game you seemed to perform a lot better when you actually thought about tactics and things like that.

The organization and structure of the lessons through this MBP appears significant in the boys' re-membering. The boys recalled that these lessons were (a) focused on them, and (b) were about each individual's development:

Guy (HA): he did it in such a different way to any other teacher...more of a focus on the technical aspect, and that helped bring everyone’s game on. Simon (MA): we weren’t just told “do this”, we were told to, we were given something with an aim at the end and we could do it our own way, and that was something that I think I'll remember because I enjoyed doing that. 
Alex (HA): it wouldn't just be going out and doing something, it would be going out, doing something and talking about it and learning about it, and thinking of better ways to improve our own games or tactics within the games.

In this sub-theme the individual boys' development of technical and tactical skills in sport is of importance in what the boys become members of - a technical sport discourse. This also involves, as MacPhail et al. (2003) highlight, general principles of sports: not about doing or playing, but about learning what to do and what it means to play sport.

Learning Beyond the Game Within an Educational Sport Discourse. The final sub-theme is about memories of learning that are beyond the game and which occur as a consequence of participating. In other words the boys' memories were more frequently of 'how' rather than 'what' - a well reported outcome of using MBP (Kirk, 2013; Sinelnikov, \& Hastie, 2008, 2010). While this sub-theme is still concerned with the basic logics of sports it is not concerned with memories of how to do sport per se, and is more concerned with memories of how lessons unfolded around ideas such as creativity, student-to-student interaction and the impact on learning, control of the educational situation, innovation, participation, democratic forms of learning, involvement, and inclusion (cf. Ennis, 2006). These values are not as frequently reported in research as the themes 'Just doing the game' and 'Learning the game' suggest. However, Kirk (2013) has shown that pedagogical models in their different forms can provide a range of educational outcomes that traditional forms of PE has not offered.

In our study, one of the boys, Guy (HA), commented on the differences in approach he enjoyed in the "learning experience" that were "different from any other physical education teacher that I’ve had previously” as it was seen to have "probably benefitted me in the long run in secondary education”. The boys were particularly taken with the idea that they weren't being treated like babies who needed to be taught the same things time and time again 
(Casey, 2013). When asked what his most important memories of physical education using MBP were, Dave (HA) recalled:

I think it was given the opportunity at the age that we were...to have that responsibility and being given that freedom, whereas, in a classroom, people were hesitant to give us that because, because of our age and because we can’t really prove ourselves to be responsible if we're not given that chance, but then, when this came in, and with Mr Casey’s techniques... we felt like we could mature and, given that responsibility and given the roles and the different roles we could do, then I always loved the fact that we could do that.

These self-same feelings of being treated like a learner in his own right were evident in Dan's (MA) memories. He suggested that, as male students, they we given “a bit more responsibility, particularly in PE. It wasn't just told this is what you do and then you go and do it, you actually had that choice, which I don’t think we'd had up until that point”. The notion of choice and increased student influence was one that was re-membered on a number of occasions (cf. Chen, Rovegno, Cone, \& Cone, 2012; Enright \& O’Sullivan, 2012). Where PE and games had been about being told what they would be doing, their MBP lessons was “a project but also PE” (Steve (MA)) in which the outcomes were co-constructed by the boys. Guy (HA) recalled:

[Single PE was] sort of the chance, as a young person, to do something that we wanted to do with sport rather than simply being told what we should do. We had the chance to develop on our own knowledge of sports previously and make a game for ourselves rather than be told a game, so I would say that was the most important memory, to expand on our own knowledge.

The games-making experience of these boys was just one example of how the 'traditional' discourse around PE was changed (Kirk, 2013). However, while there are few counter 
narratives around the positive nature of these experiences, Oliver (MA) found this approach to teaching - particularly the games-making unit - a challenge. He was sanguine enough, two years later, to acknowledge some shortcomings on his part in that if it wasn't football - “a sport I'm good at” - then he was already half way to being switched off:

If there's something that I enjoy doing, I'll give it my all [such as football which he mentioned in the rest of his interview], but I found, like, obviously others enjoyed the game, but I didn’t enjoy it, like, playing it. I quite enjoyed the, I put more of an effort in when we were doing the, like, Olympics things, but when it came to the actual making up our own game thing, I just didn't enjoy playing the game, I think, every week. That was just sort of what I thought of first, I just thought, like, playing this again, and then that's sort of how it continued, just not really having the enthusiasm to do it, I think.

For others these lessons has a positive impact on their memories, Guy (HA) in particular: I do look back on my PE times quite fondly, because I wasn’t a huge fan of PE until we started doing it in this new way, which I really, really got into, and I really, I remember enjoying it and using the Internet as well. I felt it was really good fun, especially when we invented our own games and developed them and publicized them and tried them.

This sub-theme can be positioned within an educational discourse (Kirk, 2013; Tinning, 2002) with the cultural norms around leaning in PE moving beyond playing. Indeed the boys remembered learning that was beyond their physical act of participating in PE, and although the basic logics of sports still applied, their memories nevertheless revolved around values of creativity, student influence, innovation, democratic form, involvement and inclusion. It is thus the educational values of participating in sport and not doing sport or learning what to do in sport that is at the forefront of this theme. As Max (LA) concluded "it 
was more personal learning rather than being taught”.

\section{Discussion}

Unsurprisingly, the ways in which these boys remembered PE was through sport. Given what has been written about PE it would not be hard to present a strong argument that most people would axiomatically assume that the subject is focused on technical development within a team sports environment. Indeed, across the interviews 'physical education and games’ was remembered, if not solely as rugby (which perhaps reflects the traditions of an English grammar school education) then as skills, drills and matches. There was certainly a strong consensus of opinion that, like the women in Thomas's (1985) study who played hockey, the boys did little else besides rugby. In this way PE was re-membered as (a) doing sports for real, and (b) the enjoyment, or lack of enjoyment, which the boys got as a consequence of playing. The focus was on doing and trying and the collateral learning, in Dewey’s terms, was about potentially learning to participate as a player, and to discover if they found sport fun or not, and whether they fitted into the cultural norms of sport or not.

If the study were to end there then we would have a familiar, well-documented and unsurprising account of PE bound by traditional expectations and a multi-sports discourse. Almost regardless of the sport, the boys remain positioned as players rather than learners of games, and their expectations around PE would almost certainly match those of their parents (Kirk, 2012; Tinning, 2002). Such re-membering serves only to reinforce how PE, as a school subject, is positioned and the ways in which it is valued in society.

What was clear from this study that a real sense that sport also was re-membered in different ways by the boys. Some lessons were remembered through either (a) a technical, or (b) an educational discourse, where learning occurred through and about the game. When learning through a technical discourse, the boys were positioned as learners of games (as a genre) and technique, tactics, and strategy were seen as being as important as learning the 
technical skills. In other words, the boys were not only playing the game but they were learning about what it meant to play the game, as well as what is important in order to play the game successfully. That is not to say that the vehicle for learning was any different: it was still a multi-activity curriculum through which the boys remembered learning a number of particular sports. Indeed there was no counter discourse and it was 'given' that male students should learn sports and teachers should teach them.

All the boys had strong memories of games making and yet these should also be considered as part of this sports discourse, as their memories were of learning parts of, and ideas or theories behind, sports. Even in learning what it takes to create a game the boys recognized, and described, these activities as sport. However, it is clear that the boys' memories of PE moved away from a traditional discourse (c.f. Siedentop, 1994) and focused on what they learnt, sometimes in deliberate contrast to the ideas of just doing games. In other words they felt that 'we learnt things' rather than 'we simply did them'. The collateral learning in this theme is accordingly about learning the values in and of sport, such as competition, winning, teamwork, and creating a good atmosphere.

Claims made about sport - that it builds character, makes you feel better and encourages fair play in class and in life - far outstrip any evidence that might support such an argument. However, the boys’ re-actualized memories of learning within an educational discourse suggest the breadth and depth of learning that is possible as a consequence of participating in PE. Yes, it was still contained within the basic logics of sports but their rememberings and re-actualizings were not of sports per se but were instead memories of how the lessons unfolded. They recalled inter alia creativity, student influence, control of the educational situation, innovation, participation, democratic form, involvement, and inclusion and often articulated - in much more detail than previously - memories of 'how' rather than 'what' they did in PE. The learning could thus be positioned as predominantly collateral and 
was about learning educational values like student influence, value, and democracy, values Dewey (1938) argue to be what counts in the future. It is important to note two limitations of the study. Firstly as only boys were used it may not be possible to generalize the findings to girls. Secondly, the use of a convenient sample may limit the generalizability of the findings.

\section{What Does This Article Add?}

We have indicated how memories of PE might be re-actualized in male students' stories of doing and learning sport. However memories are also formed around the educational situations in which students learn. Therefore, even if PE often looks like sports, indeed even if they do sports in PE, the learning (as explored through what they re-member and what they become (re)members of) can be quite different.

When boys recall memories of PE that move away from the cultural norms of playing or the multi-activity discourse and move towards an educative discourse where the 'how' and 'why' replace the 'what,' then re-membering becomes richer. This is something both research and practitioners of PE should pay attention to. If this re-actualization of experience is 'paid forwards' (in other words if students experience PE positively) then the impact could be significant for future generations. In seeking to shift the cultural norms we need to explore what people do and say in PE's name - both those currently involved in the field and those who influence them. This starts with the positioning of PE within the individual and cultural memories of our societies.

This study offers insight into the significance of specific memories of learning in PE alongside the general knowledge acquisition that is seen as the function of schooling. In this way it informs both research and practice regarding the importance of going beyond merely offering participatory roles to young people in sport and foreground the opportunities for them to learn sport as well as other values important for their growth - something that educational approaches such as MBP can offer to its participants in comparison to a more 
traditional curriculum.

\section{References}

Bogden, R. C., \& Biklen, S. K. (1998). Qualitative research for education: An introduction to theory and methods. London, UK: Allyn and Bacon.

Boyer, P. (2009). What are memories for? Functions of recall in cognition and culture. In P. Boyer \& J. V. Wertsch (Eds.). Memory in mind and culture (pp. 3-28) Cambridge, UK: Cambridge University Press.

Casey, A. (2011). Sport Education through the eyes of a teacher researcher and his students. In P. Hastie (Ed.) Sport Education: International Perspectives (pp. 92-104), London, UK: Routledge.

Casey, A. (2012). A self-study using action research: changing site expectations and practice stereotypes. Educational Action Research, 20(2), 219-232.

Casey, A. (2013). “Seeing the trees not just the wood”: Steps and not just journeys in teacher action research. Educational Action Research, 21(2), 146-162.

Casey, A. (2014). Models-based practice: great white hope or white elephant? Physical Education and Sport Pedagogy, 19(1), 18-34.

Casey, A., Dyson, B., \& Campbell, A. (2009). Action research in physical education: focusing beyond myself through cooperative learning, Educational Action Research, 17(3), 407-423.

Casey, A., \& Hastie, P. (2011). Students and teacher responses to a unit of student-designed games. Physical Education and Sport Pedagogy, 16(3), 295-312.

Casey, A., Hastie, P., \& Rovegno, I. (2011). Student learning during a unit of studentdesigned games. Physical Education and Sport Pedagogy, 16(4), 331-350. 
Chen, W., Rovegno, I., Cone, S. L., \& Cone, T. P. (2012). An accomplished teacher's use of scaffolding during a second-grade unit on designing games. Research Quarterly for Exercise and Sport, 83, 221-234.

Crum, B. J. (1993). Conventional thought and practice in physical education: problems of teaching and implications for change. Quest, 45, 339-356.

Dewey, J. (1926/1984). Affective thought. In J. A. Boydston (Ed.) John Dewey: the later works, volume 2 (pp. 104-115). Carbondale, IL: Southern Illinois University Press.

Dewey, J. (1938/1997). Experience and education. New York, NY: Simon \& Schuster.

Elo, S., \& Kyngäs, H. (2008). The qualitative content analysis process. Journal of Advanced Nursing, 62, 107-115.

Ennis, C. D. (1996). Students' experiences in sport-based physical education: [more than] apologies are necessary. Quest, 48, 453-456.

Ennis, C. D. (2006). Curriculum: forming and reshaping the vision of physical education in a high need, low demand world of schools. Quest, 58, 41-59.

Enright, E., \& O'Sullivan, M. (2012). Physical education “in all sorts of corners” student activists transgressing formal physical education curricular boundaries. Research Quarterly for Exercise and Sport, 83, 255-267.

Guba, E. G., \& Lincoln, Y. S. (1989). Fourth generation evaluation. Newbury Park, CA: Sage.

Jackson, P. (1968). Life in classrooms. New York, NY: Reinhart \& Winston.

Kirk, D. (2012). Defining physical education (Routledge revivals): The social construction of a school subject in postwar Britain. London, UK: Routledge.

Kirk, D. (2013). Educational value and models-based practice in physical education. Educational Philosophy and Theory, 45, 973-986.

Krefting, L. (1991). Rigor in qualitative research: the assessment of trustworthiness. The 
American Journal of Occupational Therapy, 4, 214-222.

Lincoln, Y. S., \& Guba, E. G. (1985). Naturalistic Inquiry. London, UK: Sage.

Mace, J. H., Clevinger, A. M., \& Martin, C. (2010). Involuntary memory chaining versus event cueing: Which is a better indicator of autobiographical memory organisation? Memory, 18, 845-854.

MacPhail, A., Kinchin, G., \& Kirk, D. (2003). Students’ conceptions of sport and sport education. European Physical Education Review, 9, 285-299.

Morgan, P., \& Bourke, S. (2008). Non-specialist teachers’ confidence to teach PE: the nature and influence of personal school experiences in PE. Physical Education and Sport Pedagogy, 13, 1-29

Öhman, M., \& Quennerstedt, M. (2008). Feel good—be good: subject content and governing processes in physical education. Physical Education and Sport Pedagogy, 13, 365379.

Parker, M., \& Curtner-Smith, M. (2012). Preservice teachers' use of production and reproduction teaching styles within multi-activity and sport education units. European Physical Education Review, 18, 127-143.

Pathman, T., Samson, Z., Dugas, K., Cabez, R., \& Bauer, P. J. (2011). A “snapshot of declarative memory: Differing development trajectories in episodic and autobiographical memory. Memory, 19, 825-835

Pillemer, D. B., Picariello, M. L., Law, A. B., \& Reichman, J. S. (1996). Memories of college: the importance of specific educational episodes. In D. C. Rubin (ed.) Remembering our past: studies in autobiographical memory. (pp. 318-337). Cambridge, UK: Cambridge University Press.

Pühse, U., \& Gerber, M. (Eds.). (2005). International comparison of physical education: concepts, problems, prospects. Oxford, UK: Meyer \& Meyer Sport (UK) Ltd. 
Schacter, D. L., Gutchess, A. H., \& Kensinger, E. A. (2009) Specificity of memory: implications for individual and collective remembering In P. Boyer \& J. V. Wertsch (eds.). Memory in mind and culture (pp. 83-111) Cambridge, UK: Cambridge University Press.

Siedentop, D. (1994). Sport education: quality PE through positive sport experiences. Leeds, UK: Human Kinetics Publishers.

Sinelnikov, O., \& Hastie, P. (2008). Teaching sport education to Russian students: An ecological analysis. European Physical Education Review, 14, 203-222.

Sinelnikov, O. A., \& Hastie, P. A. (2010). Students’ autobiographical memory of participation in multiple sport education seasons. Journal of Teaching in Physical Education, 29, 167-183.

Stenhouse, L. (1975). An Introduction to Curriculum Research and Development. London, UK: Heinemann.

Thomas, J. (1985). Remembrance of things past and best forgotten. Physical Education Review, 8(1): 3-6

Tinning, R. (2002). Toward a “modest pedagogy”: reflections on the problematics of critical pedagogy. Quest, 54, 224-240.

Tulving, E. (1983). Elements of episodic memory. Cambridge, UK: Cambridge University Press.

Tulving, E., \& Thomson, D. M. (1973). Encoding specifically and retrieval processes in episodic memory. Physiological Review, 80, 352-373

Wallhead, T. L., Hagger, M., \& Smith, D. T. (2010). Sport education and extracurricular sport participation: An examination using the trans-contextual model of motivation. Research Quarterly for Exercise and Sport, 81, 442-455.

Williams, H. L., \& Conway, M. A. (2009) networks of autobiographical memories. In P. 
Boyer \& J. V. Wertsch (eds.). Memory in mind and culture (pp. 33-61) Cambridge, UK: Cambridge University Press. 